\title{
Pengaruh Keselamatan Dan Kesehatan Kerja Terhadap Produktifitas Kerja Karyawan CV. Rangga Beton Pekanbaru
}

\author{
LAMIN \\ Sekolah Tinggi Ilmu Ekonomi Riau \\ Jln. HR. Subrantas 57 Panam Pekanbaru 28293 Telp. (0761) 63237 \\ E-mail : lamin@lecturer.stieriau.akbar.ac.id
}

\begin{abstract}
This study aims to determine the safety and health of work productivity of CV employees CV Rangga beton Pekanbaru. In this study data was collected through a questionnaire of 45 people. The data analysis technique used was multiple regression analysis, which served to prove the research hypothesis. The result of testing 1 is the effect of safety on employee work productivity is Safety has a significant effect on employee work productivity seen from t-count is greater than t-table (2.918> 2.018). The result of testing 2 is that the health effect on employee work productivity is health has a significant effect on employee work productivity seen from t-count is greater than t-table (4.448> 2.018). The result of testing 3 is the effect of occupational safety and health on employee work productivity. Safety and health have a significant effect on employee work productivity seen from a significance level of $0.00<0.05$. And the results of multiple linear regression show $\mathrm{Y}=\mathrm{a}+\mathrm{bX} 1+\mathrm{bX} 2$, namely: $\mathrm{Y}=-1,088+0,602 \mathrm{X} 1+0,411 \mathrm{X} 2$. From the regression equation, it can be concluded that the regression coefficient of $\mathrm{bx}$ is positive. This shows that the independent variable if it increases its equation will cause an increase in the dependent variable. the results of R Square amounted to $0.455(45.5 \%)$ explaining that employee work productivity is affected by safety and health by $45.5 \%$.
\end{abstract}

Keywords: Safety and Health, Employee Productivity

Suatu perusahaan merupakan organisasi yang terdiri dari sumber daya manusia yang memiliki tujuan yang sama untuk dicapai. Apapun tujuan tersebut secara bersama menjadi komitmen organisasi untuk selalu dijaga dan dipahami oleh sumber daya manusia yang bekerja di dalamnya. Namun di era yang semakin kompleks ini.

Karyawan CV. Rangga Beton khususnya bagian lapangan adalah orang yang paling membutuhkam jaminan keselatan karena kondisi tempat kerja mereka yang berbahaya dan beresiko tinggi. Adanya kecelakaan merupakan masalah yang sangat merugikan pekerja dan perusahaan. Pekerja dirugikan sebab mereka mengalami kesakitan,kecacatan bahkan bisa berakibat kematian.

Kerugian yang disebabkan oleh kecelakaan tersebut sangatlah besar dan kemugkinan semua pihak yang terlibat baik pekerja maupun pimpinan perusahaan dan selaku kebijakan harus memahami dan menerapkan program-program tentang Keselamatan dan Kesehatan Kerja (K3) sehingga tercipta lingkungan yang aman, nyaman dan sehat. Maka demikian jumlah kecelakaan kerja dapat ditekan dan perusahaan tidak akan mengalami suatu kerugian. Maka perlu dilakukan dengan menganalisis kecelakaan kerja sehingga dapat mengurangi atau mencegah adanya kecelakaan kerja.

Tabel 1: Kecelakaan Kerja Karyawan pada CV. Rangga Beton Pekanbaru

\begin{tabular}{|c|c|c|c|c|c|}
\hline \multirow{2}{*}{$\begin{array}{c}\text { Tah } \\
\text { un }\end{array}$} & \multicolumn{4}{|c|}{ Klasifikasi Kecelakaan } & \multirow{2}{*}{$\begin{array}{c}\text { Juml } \\
\text { ah }\end{array}$} \\
\cline { 2 - 5 } & $\begin{array}{c}\text { Karyaw } \\
\text { an }\end{array}$ & $\begin{array}{c}\text { Luka } \\
\text { Ringan }\end{array}$ & $\begin{array}{c}\text { Luka } \\
\text { Sedang }\end{array}$ & $\begin{array}{c}\text { Luka } \\
\text { Berat }\end{array}$ & \\
\hline 2014 & 46 & 20 & 5 & 4 & 29 \\
\hline 2015 & 46 & 5 & 4 & - & 9 \\
\hline 2016 & 45 & 15 & 3 & 1 & 19 \\
\hline 2017 & 45 & 22 & 8 & 1 & 31 \\
\hline 2018 & 45 & 18 & 10 & 2 & 30 \\
\hline
\end{tabular}


Sumber : CV. Rangga Beton Pekanbaru 2018

Pada tabel 1 di atas dapat dilihat besarnya tingkat kecelakaan pada karyawan yang bekerja dengan klasifikasi kecelakaan yaitu kecelakaan ringan, kecelakaan sedang, dan kecelakaan berat. Tidak dibagi berdasarkan tipe atau jenis kecelakaan tetapi dibagi berdasarkan tingkat resikonya. Dengan demikian jelaslah bahwa kecelakaan kerja merupakan salah satu sistem dimana harus terdapat penyesuaian pekerjaan terhadap pekerjaan yang dijalankannya sehingga dapat memelihara kesehatan fisik, mental, dan kesejahtraan karyawan di semua lingkungan pekerjaan.

Hasil kerja yang dicapai pada CV.Rangga beton Pekanbaru pada \% tahun terakhir ini cenderung mengalami perubahan yaitu :

Tabel 2: Produktifitas Karyawan CV. Rangga Beton Pekanbaru

\begin{tabular}{|c|c|c|c|c|}
\hline Tahun & $\begin{array}{c}\text { Jumlah } \\
\text { Karyawan }\end{array}$ & $\begin{array}{c}\text { Target Kerja } \\
\text { (Titik) }\end{array}$ & $\begin{array}{c}\text { Realisasi } \\
\text { Kerja } \\
\text { ( Titik })\end{array}$ & Persentase \\
\hline 2014 & 42 & 190 & 165 & $86 \%$ \\
\hline 2015 & 46 & 235 & 187 & $79 \%$ \\
\hline 2016 & 46 & 240 & 210 & $87 \%$ \\
\hline 2017 & 45 & 288 & 275 & $95 \%$ \\
\hline 2018 & 45 & 300 & 282 & $94 \%$ \\
\hline
\end{tabular}

Sumber : CV. Rangga Beton Pekanbaru 2018

Dari tabel diatas dapat dilihat bahwa realisasi setiap tahunnya tidak mencapai target yang telah ditetapkan. Kesadaran karyawan untuk berusaha supaya lebih giat lagi, yaitu dengan tingkat partisipasi karyawan yang tinggi terhadap hal tersebut, jelas pula dapat dikatakan bahwa keberadaan CV. Rangga beton yang perlu disesali adalah peningkatan keselamatan kerja dan kesadaran dalam mendapatkan keterampilan dan keahlian untuk mengendalikan produktifitas kerja yang dicapai.

Dari uraian-uraian diatas maka penulis tertarik untuk melakukan penelitian lebih jauh mengenai analisis perusahaan $\mathrm{CV}$. Rangga beton Pekanbaru dalam suatu penelitian dengan judul "Pengaruh Keselamatan dan Kesehatan Kerja Terhadap

Jurnal Daya Saing (Vol. 5, No. 1 Februari 2019)
Produktifitas Kerja Karyawan CV. Rangga Beton Pekanbaru".

Penelitian yang penulis lakukan ini memiliki ntujuan untuk mengetahui pengaruh keselamatan dan kesehatan kerja terhadap produktifitas kerja karyawan pada CV. Rangga Beton Pekan baru.

Setiap perusahaan selalu berusaha agar karyawan bisa berprestasi dalam bentuk memberikan produktivitas kerja yang maksimal. Produktivitas karyawan bagi suatu perusahaan sangatlah penting sebagai alat pengukur keberhasilan dalam menjalankan usaha. Karena semakin tinggi produktivitas kerja karyawan dalam perusahaan, berarti laba perusahaan semakin meningkat.

Menurut Ardana (2012:269), dari sudut filosofis produktivitas adalah suatu sikap mental yang selalu berusaha dan mempunyai pandangan bahwa mutu kehidupan hari ini lebih baik dari hari kemarin dan esok harus lebih baik dari hari ini. Menurut Wibowo (2012:109), produktivitas adalah hubungan antara keluaran atau hasil organisasi dengan masukan yang diperlukan. Menurut Sedarmayanti (2011:56), produktivitas adalah sikap mental (attitude of mind) yang mempunyai semangat untuk melakukan peningkatan perbaikan.

Menurut Nasution (2010:281), menyatakan dalam ilmu ekonomi, produktivitas merupakan nisbah atau rasio antara hasil kegiatan (output/keluaran) dan segala pengobanan (biaya) untuk mewujudkan hasil tersebut (input/masukan). Menurut Ambar Teguh Sulistiyani (2009:247), produktivitas menyangkut masalah akhir, yakni seberapa besar hasil akhir yang diperoleh di dalam proses produksi. Dalam hal ini tidak terlepas dengan efisiensi dan efektivitas.

Menurut Soeprihanto dalam Triton (2007:8), produktivitas dapat diartikan sebagai perbandingan antara hasil-hasil yang dicapai dengan keseluruhan sumber daya yang dipergunakan atau perbandingan jumlah produksi (output) dengan sumber daya yang digunakan (input).

p.ISSN: $2407-800 X \quad$ e.ISSN: 2541-4356 
Menurut Edy Sutrisno (2013:104), untuk mengukur produktivitas kerja diperlukan suatu indikator sebagai berikut :

1. Kemampuan

Mempunyai kemampuan untuk melaksanakan tugas, keterampilan yang dimiliki serta profesionalisme.

2. Meningkatkan hasil yang dicapai.

Hasil merupakan salah satu yang dapat dirasakan baik oleh yang mengerjakan maupun yang menikmati hasil pekerjaan tersebut.

3. Semangat kerja

Indikator ini dapat dilihat dari etos kerja dan hasil yang dicapai dalam satu hari kemudian dibandingkan dengan hari sebelumnya.

4. Pengembangan diri

Senantiasa mengembangkan diri untuk meningkatkan kemampuan kerja. harapan untuk menjadi lebih baik.

5. Mutu

Mutu merupakan hasil pekerjaan yang dapat menunjukkan kualitas kerja seorang pegawai. Jadi menigkatkan mutu bertujuan untuk memberikan hasil yang terbaik.

6. Efisiensi

Perbandingan antara hasil yang dicapai dengan keseluruhan sumber daya yang digunakan. Masukan dan keluaran merupakan aspek produktivitas yang memberikan pengaruh yang cukup signifikan bagi karyawan.

Perhatian terhadap keselamatan kerja dapat dipertegaskan lagi dengan memberikan pembinaan dan perlindungan pada teman kerja agar bisa terhindar dari resiko kecelakaan kerja, karena setiap tenaga kerja berhak mendapatkan perlindungan atas keselamatan dan kesehatan kerjanya seperti yang dinyatakan dalam UU RI NO.13 tahun 2003,(47-48) tentang ketenaga kerjaan yaitu pada paragrap ke 5 pasal 87 yaitu suatu konsep berfikir dan upaya nyata untuk menjamin kelestarian tenaga kerja pada khususnya dan setiap insan pada umumnya beserta hasil karya dan budayanya dalam upaya mencapai masyarakat adil, makmur, dan sejahtera. Secara keilmuan sebagai ilmu pengetahuan dan penerapan guna mencegah kemungkinan terjadinya kecelakaan atau penyakit yang disebabkan oleh pekerjaan dan lingkungan kerja.

Menurut Mangkunegara (2011:161), keselamatan kerja merupakan kondisi yang aman atau selamat dari penelitian, kerusakan atau kerugian ditempat kerja. Resiko keselamatan kerja merupakan aspek-aspek dari lingkungan kerja yang dapat menyebabkan kebakaran, ketakutan aliran listrik, perpotong, luks memsr, keseleo, patah tulang kerugian alat tubuh, penglihatan dan pandangan.

Menurut Marwansyah (2016:456) Keselamatan kerja adalah perlindungan para pekerja dari lika-luka yang diakibatkan oleh kecelakaan kerja yang berkaitan dengan pekerjaanya.

Menurut Husni (2005:136)

keselamatan kerja bertalian dengan kecelakaan yaitu kecelakaa yang terjadi ditempat kerja atau dikenal engan istilah kecelakaan industri. Kecelakaan industry ini secara umumdapat diartikan sebagai suatu kejadian yang tidak diduga semula dan dikehendaki yang mengacaukan proses yang telah diatur dari suatu aktifitas. Adapun faktor penyebab yaitu;
a. Faktor manusia
b. Faktor material/bahan/peralatan
c. Factor bahaya/sumber bahaya
d. Factor yang dihadapi (pemelihara/perawatan mesin- mesin)
Menurut Husni (2005:137) bahwa disamping ada sebabnya maka suatu kejadian juga akan membawa akibat. Akibat dari kecelakaan kerja ini dapat dikelompokan menjadi dua, yaitu:

a. Kerugian yang bersifat ekonomis, antara lain:

a. Kerusakan/kehancuran mesin, peralatan, bahan dan bangunan.

b. Biaya pengobatan dan perawatan korban

c. Tunjangan kecelakaan

d. Menurunnya jumlah maupun mutu produksi 
b. Kerugian yang bersifat non ekonomis Pada umumnya berupa penderitaan manusia yaitu tenaga kerja yang bersangkutan baik itu merupakan kematian, luka/cedera berat maupun luka ringan.

Menurut Moenir dalam Ramdan (2014:3) indikator keselamatan kerja adalah:

a. Penempatan benda atau barang yang aman

Peralatan, mesin yang dilengkapi alat alat pengaman, pengaturan tata letak, penerangan yang cukup.

b. Perlindungan kerja terhadap alatalat kerja

Menjaga agar lantai dan tangga bebas dari air, minyak dan lainnya,

c. Program sosialisasi petunjukpetunjuk keamanan

Tersedianya larangan larangan dan petunjuk pemakaian peralatan

d. Penyediaan perlengkapan sebagai alat pencegahan kecelakaan

Perlengkapan pencegahan misalnya: alat pencegahan kebakaran, pintu darurat, pertolongan apabila terjadi kecelakaan.

Menurut Sama'mur (2007:76) keselamatan kerja adalah spesialisasi dalam ilmu kesehatan/kedokteran beserta prakteknya yang bertujuan agar pekerja/masyarakat beserta memperoleh derajat kesehatan yang setinggi-tingginya, baik fisik, atau mental, maupun social, dengan usaha-usaha preventif dan kuratif, terhadap penyakit-penyakit/gangguangangguan kesehatan yang diakibatkan factorfaktornpekerjaan lingkungan kerja serta terhadap penyakit-penyakit umum.

Menurut Flippo (Mutiara, 2004:113), program kesehatan kerja dibedakan menjadi 2 (dua) yaitu:

1. Kesehatan fisik
a. Pemesriksaan jasmani pra penempatan
b. Pemeriksaaan jasmani secara berkala untuk personalia

c. Pemeriksaan jasmani berkala secara sukarela untuk semua personalia

d. Klinik medis yang mempunyai staf dan perlengkapan yang baik.

e. Tersedianya personalia medis dan ahli hygiene industry yang terlatih

f. Perhatian yang sistematik dan prefentif yang di curahkan pada tekanan yang ketegangan indrustrial.

g. Pemeriksaan-pemeriksaan berkala dan sistematis atas ketentuan untuk saanitasi yang tepat.

2. Kesehatan Mental
a. Tersedianya penyuluhan kejiwaan dan psikiater lembaga- lembaga psikiater dari luar organisasi
b. Kerja sama dengan spesialis dan
c. Pendidikan personalia perusahaan sehubungan dengan hakikat dan pentingnya masalah krsrhatan mental
d. Pengembangan dan pemeligaraan program hubungan kemanusiaan yang tepat

Indikator kesehatan kerja menurut Manullang (2006:87) adalah:

a) Lingkungan kerja secara medis

Kesehatan kerja diukur dari lingkungan kerja secara medis seperti, kebersihan lingkungan kerja, suhu udara dan ventilasi ditempat kerja, sistem pembuangan sampah dan limbah industry

b) Sarana kesehatan tenaga kerja Sarana kesehatan kerja dapat dilihat dari upaya-upaya dari organisasi untuk meningkatkan kesehatan dari tenaga kerjanya. Hal ini dapat dilihat dari penyediaan air bersih dan sarana kamar mandi

c) Pemeliharaan kesehatan tenaga kerja

p.ISSN: $2407-800 \mathrm{X}$ e.ISSN: 2541-4356 
Yaitu fasilitas pelayanan kesehatan tenaga kerja oleh pihak organisasi seperti jaminan kesehatan, dan lain-lain.

Pencapaian standar tertinggi untuk keselamatan dan kesehatan kerja karyawan adalah penting karena akan berdampak pada kinerja karyawan maupun kinerja organisasi , Marwansyah ( 2016:338 ). Suatu lingkungan kerja yang aman membuat pekerja menjadi sehat dan lebih produktif. Jika perusahaan dapat menurunkan tingkat dan beratnya kecelakaan kerja, penyakit dan hal-hal yang berkaitan dengan stress, serta mampu meningkatkan kulitas kehidupan kerja dan pekerjaannya, perusahaan akan semakin efektif. Peningkatan-peningkatan dalam hal ini akan menghasilkan meningkatnya kinerja karena menurunnya jumlah hari kerja yang hilang. Meningkatnya efisiensi dan kualitas pekerja yang lebih berkomitmen.

Kesehatan kerja dari setiap karyawan perlu mendapat perhatian sehingga mereka mendapat bekerja secar sehat tanpa membahayakan dirinya maupun masyarakat disekitar lingkungannya sehingga kinerja yang optimal dapat dicapai sesuai dengan program perlindungan karyawan.

\section{METODE}

Sejalan dengan permasalahan penelitian yang telah diuraikan diatas, maka penelitian ini dilaksanakan pada CV. Rangga beton Pekanbaru yang beralamat di Jl. Garuda Sakti KM.4.

Penelitian menggunakan dua jenis data dalam melakukan penelitian untuk membantu pemecahan masalah, yaitu: Data Premier "Sumber premier merupakan sumber data yang langsung memberikan data kepada pengumpul data.'Data premier merupakan data yang diperoleh secaa langsung dari CV. Rangga Beton Pekanbaru. Data Sekunder "Sumber sekunder merupakan sumber data yang diperoleh dengan cara membaca, mempelajari dan memahami melalui media lain sumber dari literature, buku-buku, secara dokumen perusahaan." Data sekunder merupakan data yang diperoleh dari buku- buku perusahaan dan data-data yang menunjang penelitian.

Definisi populasi menurut Sugiyono (2009:90) sebagai berikut: "Populasi merupakan wilayah generalisasi yang terdiri atas obyek atau subyek yang mempunyaikualitas dan karakteristik tertentu yang di tetapkam oleh penelitian untuk dipelajari dan kemudian ditarik kesimpulannya." Populasi dalam penelitian ini adalah semua karyawan CV. Rangga Beton Pekanbaru.yang berjumlah 45 orang. Arikunto (2010:103) mengemukakan jika populasi kurang dari 100 maka seluruh populasi dijadikan sampel. Pada penelitian ini jumlah sampel sebanyak 45 orang.

Teknik pengumpulan data berdasarkan penyebaran lembaran pertanyaan yang disebut dengan angket.

Penelitian ini menggunakan metode kuantitaif yaitu penganalisaan yang bersifat menjelaskan dan menguraikan data dan informasi yang diperoleh dengan pengukuran variabel menggunakan sakala liker's yang dikelompokkan dengan skor interval menggunakan 5 kategori yaitu : Sangat setuju (SS) nilai 5, Setuju (S) nilai 4, Cukup Setuju (CS) nilai 3, Tidak Setuju (TS) nilai 2 dan Sangat Tidak Setuju (STS) nilai 1.

Uji $F$ digunakan untuk pengujian koefisien regresi secara keseluruhan untuk menguji keberartian model yang mempengaruhi hubungan antara variable independen dan variable dependen. Pengujian signifikan persamaan regresi yang akan di peroleh dilakukan dengan menggunakan uji F.

Untuk menguji hipotesisnya secara simultan penulis mengunakan uji F(anova), dengan kriteria pengujian:

a. Apabila $\mathrm{F}$ hitung > F tabel maka hipotesanya nol ditolak dan hipotesis alternative diterima.

Apabila F hitung < F tabel maka hipotesis nol diterima dan hipotesa alternatifnya ditolak. 


\section{HASIL}

Analisis regresi linier berganda digunakan untuk menentukan hubungan yang linier antara variabel bebas terhadap variabel terikat, dan memprediksi variabel terikat. Berikut hasil out put SPSS :

Tabel 3 Analisis Regresi Linier Berganda

\begin{tabular}{|c|c|c|c|c|c|}
\hline \multirow[b]{2}{*}{ Model } & \multicolumn{2}{|c|}{$\begin{array}{l}\text { Unstandardized } \\
\text { Coefficients }\end{array}$} & \multirow{2}{*}{$\begin{array}{l}\text { Standardized } \\
\text { Coefficients } \\
\text { Beta }\end{array}$} & \multirow[b]{2}{*}{$\mathrm{t}$} & \multirow[b]{2}{*}{ Sig. } \\
\hline & B & Std. Error & & & \\
\hline 1 (Constant) & -1.088 & 7.777 & & -.140 & .889 \\
\hline kesehatan & .602 & .135 & .520 & 4.448 & .000 \\
\hline keselamatan & .411 & .141 & .341 & 2.918 & .006 \\
\hline
\end{tabular}

Berdasarkan tabel diatas diperoleh persamaan regresi linier sederhana adalah sebagai berikut : $\mathrm{Y}=-1,088+0,602 \mathrm{X} 1+$ $0,411 \mathrm{X} 2$

Persamaan tersebut dapat diartikan sebagai berikut :

a. Konstanta sebesar $-1,088$ artinya tanpa adanya keselamatan dan kesehatan, maka produktifitas kerja karyawan berkurang menjadi 1,008 satuan.

b. Nilai koefisien regresi untuk variabel keselamtan sebesar 0,411 menunjukkan arah hubungan yang positif, yaitu jika variabel keselamatan meningkat satu-satuan, maka akan meningkatkan produktifitas kerja sebesar 0,411 satuan.

c. Nilai koefesien untuk variabel kesehatan sebesar 0,602 menunjukkan arah hubungan yang positif, yaitu jika variabel kesehatan meningkat satu-satuan, maka akan meningkatkan produktifitas kerja karyawan sebesar 0,602 satuan.

Berdasarkan penjelasan diatas, maka dapat disimpulkan bahwa hasil regresi linier berganda memiliki arah hubungan yang positif, artinya adalah jika variabel bebas meningkat, maka variabel terikat akan mengalami peningkatan juga.

Pengujian ini digunakan untuk melihat apakah variabel independen mempunyai pengaruh yang signifikan terhadap variabel dependen dengan signifikansi 0,05.

Berdasarkan tabel diatas diperoleh nilai t_hitung variabel keselamatan sebesar 2,918 sedangkan untuk nilai t_tabel sebesar 2,018. maka dapat disimpulkan bahwa variabel keselamatan berpengaruh signifikan terhadap produktifitas kerja karyawan CV. Rangga Beton Pekanbaru. Berdasarkan tabel diatas diperoleh nilai t_hitung variabel kesehatan sebesar 4,448 sedangkan untuk nilai t_tabel sebesar 2,018. maka dapat disimpulkan bahwa variabel kesehatan berpengaruh signifikan terhadap produktifitas kerja karyawan CV. Rangga Beton Pekanbaru.

Berdasarkan hasil uji_t atau secara individu ( parsial ), maka dapat disimpulkan varibel bebas yang memiliki nilai pengaruh yang paling besar adalah variabel kesehatan.

Uji simultan atau uji $F$ merupakan uji secara bersama- sama untuk menguji signifikan pengaruh variabel keselamatan dan kesehatan secara bersama- sama terhadap variabel produktifitas kerja karyawanBerdasarkan tabel diatas maka diperoleh hasil regresi berganda dari tabel di atas menunjukkan nilai Sig. Sebesar $0.000<0,05$, pada tingkat kesalahan $5 \%$. Atau nilai F_hitung sebesar 18,955 maka dapat disimpulkan bahwa variabel keselamatan dan kesehatan secara bersamasama mempunyai pengaruh yang signifikan terhadap variabel produktifitas kerja CV. Rangga Beton Pekanbaru.

Koefesien determinasi ini digunakan untuk melihat kontribusi atau pengaruh yang diberikan oleh variabel bebas terhadap variabel terikat Berdasarkan tabel diatas diperoleh nilai Adjuster R Square sebesar 0,455 atau $45,5 \%$ yang memiliki arti bahwa besarnya pengaruh variabel keselamatan dan kesehatan terhadap variabel produktifitas kerja yaitu sebesar 45,5\% sedangkan sisanya sebesar 54,5\% dipengaruhi oleh variabel lain yang tidak termasuk dalam penelitian ini. 


\section{PEMBAHASAN}

Dari hasil uji Anova menunjukkan nilai F_hitung sebesar 18,955 dengan sig. Sebesar $0,000<0,05$ pada tingkat kesalahan $5 \%$ maka dapat disimpulkan bahwa keselamatan dan kesehatan secara bersamasama mempunyai pengaruh yang signifikan terhadap produktifitas kerja CV. Rangga Beton Pekanbaru. Dan sumbangan besaran pengaruh keselamatan dan kesehatan terhadap produktifitas kerja $\mathrm{CV}$. Rangga Beton Pekanbaru sebesar 45,5\%.

Dan hasil penelitian ini sejalan dengan teori yang dikemukakan oleh Marwansyah (2016:339) Program kesehatan dan keselamatan kerja dirancang untuk membuat lingkungan kerja yang aman dan memelihara kesehatan fisik maupun mental sehingga produktifitas pekerja tidak terganggu dan sangat menentukan tingkat produktifitas perusahaan secara keseluruhan. Jika perusahaan dapat menurunkan tingkat dan beratnya kecelakaan kerja, penyakit dan hal-hal yang berkaitan dengan kesehatan, serta mampu meningkatkan kulitas kehidupan kerja dan pekerjaannya, perusahaan akan semakin efektif. Peningkatan-peningkatan dalam hal ini akan menghasilkan meningkatnya kinerja karena menurunnya jumlah hari kerja yang hilang. Meningkatnya efisiensi dan kualitas pekerja yang lebih berkomitmen.

\section{SIMPULAN}

Berdasarkan hasil penelitian dan pembahasan, maka dapat disimpulkan penelitin ini, yaitu : Berdasarkan tabel olah data SPSS maka diperoleh hasil regresi berganda dari tabel di atas menunjukkan nilai Sig. Sebesar 0.000, pada tingkat kesalahan 5\%. Atau nilai F_hitung sebesar 18,955 maka dapat disimpulkan bahwa variabel keselamatan dan kesehatan secara bersamasama mempunyai pengaruh yang signifikan terhadap variabel Produktifitas kerja karyawan CV. Rangga Beton Pekanbaru.

Berdasarkan olah data SPSS diperoleh persamaan regresi linier sederhana adalah sebagai berikut : $\mathrm{Y}=-1,088+$ $0,602 \mathrm{X} 1+0,411 \mathrm{X} 2$, Persamaan tersebut dapat diartikan sebagai berikut : Konstanta sebesar -1,088 artinya tanpa adanya keselamatan dan kesehatan, maka produktifitas kerja karyawan CV. Rangga Beton Pekanbaru berkurang menjadi 1,008 satuan. Nilai koefisien regresi untuk variabel keselamatan sebesar 0,411 menunjukkan arah hubungan yang positif, yaitu jika variabel keselamatan meningkat satu-satuan, maka akan meningkatkan produktifitas kerja karyawan $\mathrm{CV}$. Rangga Beton Pekanbaru sebesar 0,411 satuan. Nilai koefesien untuk variabel kesehatan sebesar 0,602 menunjukkan arah hubungan yang positif, yaitu jika variabel kesehatan meningkat satu-satuan, maka akan meningkatkan produktifitas kerja karyawan CV. Rangga Beton Pekanbaru sebesar 0,602 satuan.

Berdasarkan olah data SPSS diperoleh nilai Adjuster R Square sebesar 0,455 atau 45,5\% yang memiliki arti bahwa besarnya pengaruh variabel keselamatan dan kesehatan terhadap variabel produktifitas kerja yaitu sebesar 45,5\% sedangkan sisanya sebesar 54,5\% dipengaruhi oleh variabel lain yang tidak termasuk dalam penelitian ini.

\section{DAFTAR RUJUKAN}

Ardana, I Komang 2012. Manajemen Sumber Daya Manusia. Graha Ilmu. Yogyakarta.

Arikunto, Suharsimi. 2010. Prosedur Penelitia., Rineka Cipta. Jakarta.

Husni, 2005 Hukum Ketenaga Kerjaan.Ed. Revisi. Jakarta:PT. Raja Grafinso

Mangkunegara, A.A. Anwar Prabu. 2011. Manajemen Sumber Daya Manusia Perusahaan. Bandung: Penerbit PT Remaja Rosdakarya

Manullang, 2006 Manajemen Personalia Yogyakarta Gajah Mada University Press

p.ISSN: $2407-800 X \quad$ e.ISSN: 2541-4356 
Marwansyah 2016, Manajemen Sumber Daya Manusia. Bandung, Alfabeta.

Nasution, Mulia, 2010, Manajemen Personalia (Aplikasi dalam Perusahaan), Jakarta, Penerbit Djambatan.

Panggabean, Mutiara Sibarani. 2004 Manajemen Sumber Daya Manusia. cetakan ke 2 Ghalia Indonesia", Jakarta

Ramdan, Bayu DKK. 20142013 Pengaruh Keselamatan dan Kesehatan Kerja (K3) terhadap Motivasi Kerja Karyawan Jurnal Administrasi Bisnis Vol 10 Univ. Brawijaya.

Sedarmayanti. 2011 manajemen Sumber Daya Manusia. PT. Refika Aditama. Bandung.
Suma'mur. 2007. Keselamatan Kerja dan Pencegahan Kecelakaan.Jakarta :Gunung Agung

Sugiyono. 2009. Metode Penelitian Bisnis. Bandung : Alfabeta

Sutrisno, Edy. 2013. Manajemen Sumber Daya Manusia. PT. Kencana. Jakarta.

Triton, PB. 2007. Manajemen Mutu Sumber Daya Manusia : Perspektif Partnership dan Kolektivitas. Penerbit Tugu. Yogyakarta.

Wibowo.2012, Manajemen Kinerja, Jakarta, Rajawali Pers. 